\title{
PAHAM KEDAULATAN NEGARA DITINJAU DARI SIFAT \\ UNIVERSILATAS HUKUM INTERNASIONAL
}

\author{
Siti Sumartini \\ Universitas Wiralodra, Indramayu \\ Email: sitisumartini_unwir@yahooo.co.id
}

\begin{abstract}
The power of theories regarding the principle of sovereignty and equality of the state began to diminish. Every independent country is a sovereign country. they are free to make policies to regulate the economic, political, legal and other systems within their country, however, today's development experiences a shift in meaning, what was previously the authority or full sovereign action of a country has diminished its understanding when the interests of other countries are disrupted or international needs require state sovereignty to be subject to universal rules and highest norms (erga omnes). In this study using a normative juridical approach and descriptive analytical research specifications. The data used in this study are secondary data consisting of primary, secondary and tertiary legal materials. Data obtained through library studies in the form of legislation, books, journals, and authoritative electronic media. The results of this study are 2 (two) explanations, namely First. that state sovereignty does not conflict with the international legal system, that state sovereignty can be used in the framework of forming an international legal system. Secondly, the universality of international law provides restrictions on the sovereignty of the state to be applied properly and the principle of respecting universal values in order to maintain human dignity and their life.
\end{abstract}

Keywords: souverignity of state and universality of international law

\section{PENDAHULUAN}

Sesungguhnya adanya hukum internasional itu secara logis menganggap terlebih dahulu adanya suatu masyarakat internasional yang telah diatur oleh sistem hukum tersebut, dengan perkataan lain, untuk dapat meyakini adanya atau lebih tepat lagi perlu adanya hukum internasional, terlebih dahulu harus ditunjukkan adanya suatu masyarakat internasional sebagai landasan sosiologis hukum internasional. Representasi masyarakat internasional dalam sistem hukum internasional adalah negara. $^{167}$

167 Mochtar Kusumaatmadja dan Etty R Agoes, Pengantar Hukum Internasional, Bandung, Alumni, 2003,hlm. 11. 
Masyarakat international dewasa ini dalam konstruksi yuridis politis adalah negara. Didalam sistem hukum internasional tidak ada kekuasaan tertinggi yang dapat memaksakan keputusan-keputusannya kepada negara, serta tidak ada satu pun badan legeslatif internasional yang membuat ketentuan-ketentuan yang dapat mengikat secara langsung negara-negara anggota, disamping hal tersebut juga tidak adanya lembaga polisional yang dapat melaksanakan sanksi-sanksi kepada negara-negara yang dianggap sebagai pelanggar hukum. ${ }^{168}$

Demikian selanjutnya daalam perkembangan kemunculan negara-negara nasional. Dalam perkembangan dan perjalanan negara-negara sampai pada era globalisasi ${ }^{169}$ sekarang ini, telah di jelaskan oleh Thomas Magstadt bahwa;

Today, we find nation-states in every region of the world, but this remarkable fact is a testament to the success of one region, Europe, in gaining temporary mastery over all the others. The point is not that one region is better than another, but rather that it is impossible for us to make sense of the modern world without giving due consideration to the role of regions as well as nationstates. ${ }^{170}$

Pada sisi lain James J Sheehan mengemukakan pandangan yang sangat kritis, bahwa salah satu permasalahan terkait konsep kedaulatan (sovereignty) adalah tentang definisi. Kedaulatan adalah suatu konsep politik, namun demikian, tidak seperti halnya konsep tentang demokrasi atau monarki; kedaulatan bukanlah tentang tempat kekuasaan itu berada. Kedaulatan tidak sama halnya dengan parlemen atau birokrasi; karena kedaulatan tidak menggambarkan institusi-institusi yang menjalankan kekuasaan. Kedaulatan juga tidak dapat disamakan dengan tertib hukum (order) maupun keadilan (justice) ; karena kedaulatan tidak menggambarkan tujuan dari pelaksanaan kekuasaan. Kedaulatan adalah suatu hal dan meliputi banyak hal. ${ }^{171}$

168 Boer Mauna, Hukum Internasional Pengertian, Peranan dan Fungsi dalam Era Dinamika Global, Bandung, Alumni, 2011 hlm.1

${ }^{169}$ Pengertian globalisasi secara literasi dikutip dari pendapat Rowman \& littlefield ( 2004;10) menjelaskan pemahaman globalisasi sebagai a process of blending or homogenization by which the people of the world are unified into a single society and function together; this process ia a combination of economics technological, sosicultural, and political forces; sedangkan menurut KBBI adalah : proses masuknya ke ruang lingkup dunia.

${ }^{170}$ Thomas Magstadt, Nations and Goverments, Sixth Edition, Boston-USA, Wadsworth Publishing, 2011, hlm.3.

${ }^{171}$ Sigit Riyanto, "Kedaulatan Negara dalam Kerangka Hukum Internasional Kontemporer"Yustisia Vol.1 No. 3 September - Desember 2012, hlm.7 
Selanjutnya sistem hukum internasional dapat direfleksikan sebagai himpunan peraturan-peraturan dan ketentuan-ketentuan yang mengikat serta mengatur hubungan antara negara-negara dan subyek-subyek hukum lainnya dalam kehidupan masyarakat internasional. ${ }^{172}$ Pada sisi lain Baderman terkait kedudukan sistem hukum internasional menjelaskan "Public international law is its own legal system, with unique ways of making and enforcing rules. But because of its sense of separation from municipal or domestic legal systems, international law has been criticized as not being law at all. ${ }^{173}$ Dalam hal ini hukum internasional sudah seharusnya mencerminkan nilai-nilai yang besifat universal yang berakar dari nilai-nilai kearifan bangsa-bangsa di dunia.

Namun demikian dalam konsep hukum internasional dikenal suatu peremptory norms (norma-norma dasar) yang merupakan nilai-nilai yang bersifat esensial dan bertujuan untuk melindungi nilai-nilai dan kepentingan-kepentingan masyarakat internasional sebagai suatu keseluruhan. Norma-norma dasar tersebut (peremptory norms) juga dikuti dengan kewajiban-kewajiban yang lahir dari hukum internasional (erga omnes). ${ }^{174}$

Dari penjelasan dibagian pendahuluandiatas yang menjadi fokus permasalahan penulisan ini adalah :

1. Bagaimana kedudukan kedaulatan negara modern dalam sistem hukum internasional?

2. Apakah sifat universalitas hukum internasional dapat menwujudkan ketertiban masyarakat internasional?

\footnotetext{
172 Boer Mauna, Op cit, hlm.2.

173 David J. Bederman,The Spirit of International Law, Georgia USA, The University of Georgia Press, 2002, hlm.1, lebih jauh dikatakan : "International law still labors under what might be called the Austinian critique and other forms of extreme skepticism. John Austin observed in 1832 that "the duties which [the law of nations] imposes are enforced by moral sanctions" only and that because international law lacks a supreme legislator, a coercive sovereign, and an authoritative law interpreter, it can only be regarded as "positive international morality"... "Identifying a basis of obligation in international law - and answering the seemingly simple inquiry of why states and other transnational actors obey international law rules - is thus essential for capturing the spirit of international law."

${ }^{174}$ Christian J. Tams, Enforcing Obligations Erga Omnes in International Law, New York, Cambridge University Press, 2005, hlm.3.
} 


\section{METODE}

Penelitian ini menggunakan metode pendekatan Yuridis Normatif, yaitu penelitian dengan pendekatan yang lebih ditekankan pada data-data sekunder berupa bahan-bahan hukum primer, sekunder maupun tersier. Pada penelitian hukum normatif, bahan pustaka merupakan data dasar dalam (ilmu) penelitian yang digolongkan sebagai data sekunder. ${ }^{175}$ Spesifikasi penelitian ini adalah deskriptif analitis, yaitu penelitian yang bertujuan menggambarkan mengenai fakta-fakta disertai analisis yang akurat mengenai peraturan perundang-undangan yang berlaku baik nasional maupun internasional dihubungkan dengan teori-teori hukum yang berkaitan dengan pembangunan hukum. Soerjono Soekanto mengemukakan bahwa penelitian deskriptif yaitu memberikan data yang seteliti mungkin tentang manusia, keadaan dan gejala - gejalan lainnya, dengan tujuan mempertegas hipotesa - hipoesa supaya dapat membantu dalam memperkuat teori - teori lama, atau dalam kerangka menyusun teori baru. ${ }^{176}$

Teknik pengumpulan data dilakukan melalui Penelitian kepustakaan dan Penelitian di lapangan. Penelitian kepustakaan dilakukan untuk memperoleh bahanbahan hukum baik primer, sekunder, maupun tersier. Bahan hukum primer adalah bahan-bahan yang berasal dari peraturan perundang-undangan, konvensi internasional, perjanjian internasional yang relevan. Bahan hukum sekunder yakni terdiri dari doktrin-doktrin, pendapat para ahli yang dapat terlihat dalam buku-buku hukum dan makalah-makalah yang ditulis oleh para ahli, karangan berbagai panitia pembentukan hukum, hasil penelitian hukum, RUU dan lain-lain yang dapat memberikan penjelasan mengenai bahan hukum primer. Di samping itu dikaji pula bahan hukum tersier, yakni berupa pendapat-pendapat atau opini masyarakat yang ada di dalam majalah-majalah dan surat kabar, kamus, ensiklospedi, yang dapat memberikan petujuk maupun penjelasan terhadap bahan hukum primer maupun sekunder.

Teknis Analisis data yang digunakan dalam penelitian ini adalah deskriptif analisis normatif, yakni pemaparan dan penggambaran peraturan perundang-undangan

\footnotetext{
175 Soerjono Soekanto dan Sri Maudji, Penelitian Hukum Normatif Suatu Tinjauan Singkat, Jakarta: Raja Grafindo Persada, 1985, hlm 24

176 Soerjono Soekanto, Pengantar Penelitian Hukum, Jakarta: Universitas Indonesia Press, 1984, hlm 10 .
} 
yang berkitan dengan pembentukan hukum yang dianalsis berdasarkan teori-teori hukum.

\section{PEMBAHASAN}

\subsection{Kedaulatan Negara Diatur Dalam Perspektif Hukum Internasional.}

Charles Loyseau dalam Kriegel mengatakan bahwa negara memiliki kedaulatan, kedaulatan negara digambarkan sebagai..sovereignty is the defining moment and culmination of power, the moment when the State must come into being"... Sovereignty is the form which gives being to the state; it is inseparable from the state; without it, the state vanishes. ${ }^{177}$ Jadi kedaulatan adalah momen yang menentukan dan merupkan puncak dari kekuasaan, pada saat ketika Negara harus mewujudkan dirinya "...lebih jauh dijelaskan bahwa kedaulatan adalah bentuk yang memberikan keberadaan kepada negara; ia tidak dapat dipisahkan dari negara; tanpanya, negara lenyap. ${ }^{178}$ Oleh karena itu kekuasaan tertinggi yang merupakan penjelmaan dari seluruh rakyat inilah yang kemudian disebut sebagai "leges imperii". 179

Konteks kedaulatan negara menurut Mochtar menjelaskan bahwa paham kedaulatan negara adalah terbatas, dan batasan ini ada karena ada kedaulatan negara lainnya. Mencakup didalam paham keadulatan ini adalah kemerdekaan dan persamaan derajat, artinya bahwa negara-negara yang berdaulat itu adalah negara yang merdeka (independence) juga memiliki kesamaan derajat (equality) satu dengan lainnya. Hal ini menjadi jelas bahwa paham kedaulatan, kemerdekaan dan persamaan derajat negara tidak bertentangan dengan konsep masyarakat internasional yang diatur oleh suatu sistem hukum yakni hukum internasional. ${ }^{180}$

Konsepsi kedaulatan baik yang dijelaskan oleh Bodin ataupun Austin dewasa ini sudah tidak dapat dilaksanakan secara konsekuen, karena aspek kedaulatan yang disodorkan bersifat intern saja hanya dimaksudkan untuk mengatur masyarakat

177 Blandine Kriegel et.al, The State and The Rule of Law, New Jersey, Princeton University Press, 1995, hlm.15.

178 Ibid

179 Yudha Bhakti, Imunitas Kedaulatan Negara, Di Forum Pengadilan Asing, Bandung, Alumni, 1999, hlm.179.

${ }^{180}$ Mochtar Kusumaatmadja dan Etty R Agoes, op.cit. hlm.19. 
didalam suatu negara, sedangkan kenyataan sekarang ini negara sudah merupakan bagian dari masyarakat internasional, dimana hubungan antar negara merupakan kebutuhan yang terus berkembang sedemikian luas. ${ }^{181}$ Disamping itu kemajuan teknologi dan komunikasi mengakibatkan aktivitas ekonomi (gobalisasi) tidak lagi terkungkung oleh batas-batas negara.

Pada sisi lain negara telah memiliki kedudukan yang sangat penting dan utama (par excellence) dalam sistem hukum internasional, negara menurut Raustiala juga dikatakan.."unbundling the state and reconnecting the constituent parts across national borders creates a conceptual reconfiguration of state power that, while markedly new, retains the state as the pivotal actor of the international system. in this argument; that the state remains the primary site of power and law in the international system, though it exercises this power in a disaggregated manner. ${ }^{182}$ Dari pernyataan tersebut dimaknai bahwa negara dapat menciptakan dan menghubungkan kembali konstituen yang melintasi batas nasional satu negara serta dapat membentuk konfigurasi kekuatan negara secara konseptual, serta dapat mempertahankan negara sebagai aktor penting dari sistem hukum internasional. dalam argumen ini; bahwa negara tetap menjadi aktor atau subyek utama atas kekuasaan dan hukum dalam sistem internasional, meskipun negara menjalankan kekuasaan ini secara terbagi bagi. ${ }^{183}$

Lahirnya berbagai bentuk kerjasama internasional telah memberikan pengaruh yang signifikan terhadap terhadap fungsi dari kedaulatan negara dan sekaligus sebagai bukti dari terwujudnya perkembangan hukum internasional itu sendiri, hal ini ditegaskan oleh penjelasan Clarence Diaz bahwa.." in an increasingly globalized and interdependent world, international law is growing in importance not because of positivist justifications, but because a large range of activities and actors (transnational corporations, for example) are creating international consequences and necessitating international regulation and actions." 184 Bahkan lebih lanjut

181 Eddy Purnama, Negara Kedaulatan Rakyat, Analisis Terhadap Sistemm Pemerintahan Indonesia dan Perbandingannya dengan Negara-Negara Lain, Bandung, Nusamedia, 2007, hlm. 30

182 Kal Raustiala, "The Architecture of International Cooperation: Transgovernmental Networks and the Future of International Law,” Research Paper No. 02-26, UCLA School of Law, hlm. 11.

183 Ibid

${ }^{184}$ Clarence J. Diaz, International Law and International Relations; Bridging Theory and Practice; from competition to complementarity, New York, Routledge, 2007. hlm.280. 
dikatakan oleh Diaz bahwa peran negara-negara dalam melakukan negosiasi, perancangan dan pemberlakuaan perjanjian internasional sebagai suatu instrument hukum, dan penggunaan lembaga-lembaga serta instrument internasional telah menaikan kedudukan hukum internasional dewasa ini. ${ }^{185}$

Demikan juga yang dijelaskan oleh ahli hukum internasional lainnya yang menjelaskan Pemahaman tersebut sejalan dengan apa yang telah dikemukakan oleh Shaw yang menjelaskan bahwa..while the legal structure within all but the most primitive societies is hierarchical and authority is vertical, the international system is horizontal, consisting of over 190 independent states, all equal in legal theory (in that they all possess the characteristics of sovereignty) and recognising no one in authority over them." 186 Artinya bahwa dalam suatu tatanan masyarakat yang primitif struktur hukum dimaknai secara hirarkis dan kewenangan (otoritas) bersifat vertikal, akan tetapi berbeda dalam sistem hukum internasional yang bersifat horisontal, yang terdiri lebih dari 190 negara yang memiliki kedudukan sederajat di dalam sistem hukum (karena mereka sama memiliki kedaulatan) dan tidak mengakui adanya kedaulatan yang lain di atas mereka.

Dalam era globalisasi ini, interaksi dan intensitas hubungan antar negara telah semakin meningkat antara lain ditandai dengan dicapainya berbagai kesepakatan kerja sama baik yang bersifat bilateral, regional maupun multilateral. Berbagai kesepakatan tersebut lazimnya dituangkan dalam suatu bentuk perjanjian internasional meliputi berbagai bidang termasuk politik, ekonomi, perdagangan, hukum, pertahanan, sosial budaya dan lain sebagainya. ${ }^{187}$

Kekuatan teori-teori mengenai prinsip kedaulatan dan persamaan negara mulai berkurang. Setiap negara yang merdeka adalah negara yang berdaulat. Mereka bebas membuat kebijakan-kebijakan guna mengatur sistem ekonomi, poltik, hukum dan lain-lain dalam negerinya, namun demikian perkembangan dewasa ini mengalami pergeseran makna, apa yang sebelumnya menjadi kewenangan atau tindakan berdaulat penuh suatu negara menjadi berkurang pengertiannya manakala kepentingan negara

\footnotetext{
185 Ibid

${ }^{186}$ Malcolm N.Shaw, International Law, Sixth edition, Cambridge UK, Cambridge University Pres, 2008, hlm.6.

${ }^{187}$ Eddy Pratomo, Hukum Perjanjian Internasional (Pengertian, Status Hukum, Dan Ratifikasi), Bandung, Alumni, 2011, hlm.1.
} 
lain terganggu. Negara-negara mematuhi hukum internasional karena kepatuhan tersebut di perlukan untuk mengatur hubungan antara satu dengan yang lain dan untuk melindungi kepentingan negara itu sendiri. Negara tersebut patuh karena merupakan kepentingan mereka untuk berbuat demikian. ${ }^{188}$

\subsection{Universalitas Sebagai Karakteristik Hukum Internasional}

Hukum Internasional maupun hukum positif adalah suatu aturan yang mengatur kehidupan manusia, baik skala lokal, regional maupun internasiona. Hal senada juga telah dijelaskan oleh Weeramantry yang mengartikan bahwa peran dan tanggung jawab hukum sangat diperlukan dalam suatu aturan hukum yang kuat dikarenakan fungsi hukum diadakan tidak hanya untuk hukum itu sendiri dan ketertiban global namun juga untuk kelangsungan hidup sistem masyarakat yang berkelanjutan. Hal ini dikatakan oleh Weeramantry sebagai "It has a special mission in that it bears the responsibility not merely for global law and order but for the very survival of humanity. If it fails we may well be reduced to contemplating the fading embers of dying civilizations rather than the promise of a brand new world of unsurpassed achievement. ${ }^{189}$

Lebih jauh dikatakan dalam filsafat positivisme bahwa hukum internasional dikonsepsikan sebagai a set of rules yang netral dan tidak berpihak yang bertujuan untuk mengatur kehidupan masyarakat internasional. ${ }^{190}$ Dalam hal ini hukum internasional sudah seharusnya mencerminkan nilai-nilai yang besifat universal yang berakar dari nilai-nilai kearifan bangsa-bangsa di dunia.

Demikan selanjutnya bahwa hukum internasional bersifat universal, universal diartikan oleh Antony Anghie sebagai suatu..this universality lay in the fact that those who had been excluded from the realm of sovereignty were now included and could

\footnotetext{
${ }^{188}$ Mahendra Putra Kurnia, Ketika Hukum Berhadapan Dengan Globalisasi, Malang, Universitas Brawijaya Press, 2011, hlm.15

189 C.G Weeramantry, Universalising International Law, Netherlands, Martinus Nijhoff Publishers, 2003, hlm.2.

${ }^{190}$ FX Adji Samekto,et al. Integrasi Kepentingan Kapitalisme dalam Hukum Internasional di Era Globalisasi;(Peran Hukum Dalam Pembangunan Hukum di Indonesia Kenyataan Harapan dan Tantangan), Bandung ,PT Remaja Rosdakarya, 2013, hlm.10.
} 
participate in the international system on the footing of sovereign equals. ${ }^{191}$ Penjelasan tersebut mengandung pemahaman bahwa aspek universalitas tersebut diletakkan pada kedaulatan negara dan bahwa kedaulatan suatu negara harus dibarengi dengan pertisipasai dalam lingkup sistem internasional sehingga akan terbentuk keseimbangan dalam penerapan aspek kedaulatan tersebut.

Pada sisi lain hukum internasional (internasional law) juga memiliki karakter yang berbeda dengan sistem hukum positif (municipal law), seperti yang telah dijelaskan sebagai "one of the ways in which international law is affected by the complex and contradictory nature of international governance is through the emergence of several overlapping and competing normative orders". ${ }^{192}$ Penjelasan tersebut dapat dimaknai bahwa hukum internasional dipengaruhi oleh sifat kompleksitas dan kontradiktif dari "pemerintahan" (rule) internasional melalui munculnya beberapa normatif yang tumpang tindih dan bersaing satu norma dengan lainnya. Lebih jauh dengan mengadopsi istilah dari Hedley Bull dikatakan..”several scholars have raised the question whether contemporary international society can be characterized in terms of "new medievalism"; that is: in terms of a system where each ruler has to share authority with thers and which is characterized by overlapping authority and multiple loyalty." 193 Dari pernyataan tersebut muncul suatu pertanyaan dari beberapa sarjana telah mengajukan pertanyaan apakah masyarakat internasional kontemporer (modern) dapat dicirikan dengan istilah "abad pertengahan baru"; yaitu: dalam hal sistem di mana setiap penguasa harus berbagi otoritas (kewenangan) dengan mereka dan yang ditandai dengan adanya tumpang tindih otoritas dan loyalitas ganda.

Dilihat dari perkembangan perjalanan keberadaan hukum internasional bahwa setelah pasca kolonisasi bahwa sudah lazim dalam teks standar hukum internasional untuk mengamati setelah terjadinya dekolonisasi (kemerdekaan negara-negara nasional, hukum internasional menjadi benar-benar universal dan komunitas nyata dengan terbentuknya negara-negara. Sifat universalitas hukum internasional terletak

191 Sundhya Pahuja, "The Postcoloniality of International Law"; Harvard International Law Journal; Harvard USA; Vol. 46, No 2, 2005, hlm.462.

${ }^{192}$ Ige F. Dekker and Wouter G. Werner, Governance and International Legal Theory, Leiden, Martinus Nijhoff Publishers,2004, hlm.15.

${ }^{193}$ H. Bull, The Anarchical Society: A Study of Order in World Politics (London and Basingstoke, Macmillan, 1977, hlm. 254 
pada fakta. ${ }^{194}$ Disamping itu negara-negara dalam konteks partisipasi dalam mewujudkan hubungan internasional didasarkan pada pemahaman kesamaan kedaulatan, sehingga dengan demikian dapat dikatakan bahwa hukum internasional dapat mewujudkan hubungan yang bersifat universal. ${ }^{195}$

Dalam persoalan persoalan yang berkaitan dengan hukum internasonal ditekankan juga bahwa...relevant international law in this context includes prohibitions on use of force; prohibitions on interference in the international affairs of another state, prohibitions on provision of assistance to terrorists, international humanitarian law, international human rights law, and the prohibition of genocide. ${ }^{196}$ Dapat dijelaskan bahwa hukum internasional juga mengatur persoalan mencakup larangan penggunaan kekuatan; larangan campur tangan dalam urusan internasional negara lain, larangan pemberian bantuan kepada teroris, hukum humaniter internasional, hukum hak asasi manusia internasional, dan larangan genosida.

Dari penjelasan di atas dipahami bahwa antar kedaulatan dan sifat universalitas hukum internasional saling mendukung selama prinsip kedaulatan diterapkan secara proporsional. Dipahami juga bahwa sebenarnya kedaulatan dan kesederajatan negara merupakan atribut yang melekat pada negara merdeka sebagai subyek hukum internasional. Pengakuan terhadap kedaulatan negara dan kesederajatan antar negara juga merupakan dasar bagi personalitas negara dalam sistem hukum internasional. ${ }^{197}$ Kedaulatan mendasari beberapa hak yang diakui oleh hukum internasional seperti misalnya; hak kesederajatan (equality), yurisdiksi wilayah (territorial jurisdiction), hak untuk menentukan nasionalitas bagi penduduk di wilayahnya, hak untuk

${ }^{194}$ Lihat Sundhya Pahuja, Op.cit, hlm. 461-462.

195 Ibid ; dengan penjelasan lebih lanjut.. that those who had been excluded from the realm of sovereignty were now included and could participate in the international system on the footing of sovereign equals; It could be argued, though, that, given the fact international law had already become universally applicable during the period of colonization as thedeterminative system of law governing relations over the whole of the globe, this shift was not a shift toward universality as such, but instead from one universalism to another. This shift would then illustrate the postcoloniality of international law.

196 Thomas J. Biersteker et al,International Law and International Relations Bridging theory and practice, New York, Routledge, 2007, hlm.35

${ }^{197}$ Ian Brownlie, Principles of Public International Law. Fourth Edition. Oxford : Clarendon Press, 1990, hlm 287 
mengijinkan dan menolak atau melarang orang untuk masuk dan keluar dari wilayahnya, hak untuk melakukan nasionalisasi. ${ }^{198}$

\section{PENUTUP}

1. Bahwa kedaulatan suatu negara merupakan atribut dari negara merdeka dan digunakan oleh negara tersebut untuk mengatur kehidupan rakyatnya dan melindungi wilayahnya disamping itu juga untuk dapat dijadikan sarana dalam melakukan hubungan internasional yang diatur oleh sistem hukum internasional.

2. Dalam filsafat positivisme dikatakan bahwa hukum internasional dikonsepsikan sebagai a set of rules yang netral dan tidak berpihak yang bertujuan untuk mengatur kehidupan masyarakat internasional. oleh karenanya dengan sifat universalitasnya sistem hukum internasional dapat menjaga keberadaan umat manusia.

\section{DAFTAR PUSTAKA}

\section{Buku :}

Bederman J David, The Spirit of International Law, Georgia USA, The University of Georgia Press, 2002;

Boer Mauna, Hukum Internasional Pengertian, Peranan dan Fungsi dalam Era Dinamika Global, Bandung, Alumni, 2011;

Blandine Kriegel et.al, The State and The Rule of Law, New Jersey, Princeton University Press, 1995;

C.G Weeramantry, Universalising International Law, Netherlands, Martinus Nijhoff Publishers, 2003;

Diaz J. Clarence, International Law and International Relations; Bridging Theory and Practice; from competition to complementarity, New York, Routledge, 2007

Eddy Pratomo, Hukum Perjanjian Internasional (Pengertian, Status Hukum, Dan Ratifikasi), Bandung, Alumni, 2011;

Eddy Purnama, Negara Kedaulatan Rakyat, Analisis Terhadap Sistemm Pemerintahan Indonesia dan Perbandingannya dengan Negara-Negara Lain, Bandung, Nusamedia, 2007;

198 R.C. Hingorani, Modern International Law. Second Edition. New Delhi: Oxford \& IBH Publishing Co, 1982, hlm 117-118 
FX Adji Samekto,et al. Integrasi Kepentingan Kapitalisme dalam Hukum Internasional di Era Globalisasi;(Peran Hukum Dalam Pembangunan Hukum di Indonesia Kenyataan Harapan dan Tantangan), Bandung ,PT Remaja Rosdakarya, 2013;

H. Bull, The Anarchical Society: A Study of Order in World Politics (London and Basingstoke, Macmillan, 1977;

Ian Brownlie, Principles of Public International Law. Fourth Edition. Oxford : Clarendon Press, 1990;

Ige F. Dekker and Wouter G. Werner, Governance and International Legal Theory, Leiden, Martinus Nijhoff Publishers,2004;

Malcolm N.Shaw, International Law, Sixth edition, Cambridge UK, Cambridge University Pres, 2008;

Magstadt Thomas, Nations and Goverments, Sixth Edition, Boston-USA,Wadsworth Publishing, 2011;

Mahendra Putra Kurnia, Ketika Hukum Berhadapan Dengan Globalisasi, Malang, Universitas Brawijaya Press, 2011

R.C. Hingorani, Modern International Law. Second Edition. New Delhi: Oxford \& IBH Publishing Co, 1982;

Thomas J. Biersteker et al,International Law and International Relations Bridging theory and practice, New York, Routledge, 2007;

Yudha Bhakti, Imunitas Kedaulatan Negara, Di Forum Pengadilan Asing, Bandung, Alumni, 1999;

\section{Jurnal :}

Kal Raustiala, "The Architecture of International Cooperation: Transgovernmental Networks and the Future of International Law," Research Paper No. 02-26, UCLA School of Law;

Sigit Riyanto, "Kedaulatan Negara dalam Kerangka Hukum Internasional Kontemporer"Yustisia Vol.1 No. 3 September - Desember 2012

Sundhya Pahuja, "The Postcoloniality of International Law"; Harvard International Law Journal; Harvard USA ; Vol. 46, No 2, 2005. 